\title{
The effectiveness of EGFR-TKIs against brain metastases in EGFR mutation-positive non- small-cell lung cancer
}

This article was published in the following Dove Press journal:

OncoTargets and Therapy

27 April 2017

Number of times this article has been viewed

\section{Hao Bai* \\ Liwen Xiong* \\ Baohui Han}

Department of Respiratory Medicine, Shanghai Chest Hospital, Shanghai Jiao

Tong University, Shanghai, China

*These authors contributed equally to this work
Correspondence: Baohui Han Department of Respiratory Medicine, Shanghai Chest Hospital, Shanghai Jiao Tong University, No. 24I, West Huaihai Rd, 200030 Shanghai, China Email hanbaohuichest@I63.com
Abstract: Brain metastases are usual in non-small-cell lung cancer (NSCLC) with poor prognosis and few available therapeutic options. This retrospective study aims to evaluate the efficacy of epidermal growth factor receptor-tyrosine kinase inhibitors (EGFR-TKIs) against brain metastases from NSCLC harboring activating EGFR mutation. A total of 148 patients with brain metastases from $E G F R$ mutation-positive NSCLC were analyzed retrospectively. The patients were orally given gefitinib $(250 \mathrm{mg})$ or erlotinib $(150 \mathrm{mg})$ once a day until intracranial disease progression, death, or intolerable side effects. A survival analysis was done using the Kaplan-Meier analysis and log-rank test. Objective response rate and disease control rate within brain lesions were $36.5 \%$ and $87.2 \%$, respectively, with a median progression-free survival (PFS) and overall survival (OS) of 11.2 months (95\% confidence interval [CI], 10.1-12.3) and 13.6 months (95\% CI, 12.3-14.9), respectively. The patients' characteristics were not statistically associated with PFS and OS. EGFR-TKIs showed promising antitumor activity against brain metastases in NSCLC patients with activating EGFR mutation and might be the treatment choice in this clinical setting.

Keywords: brain metastases, non-small-cell lung cancer, mutation, EGFR inhibitors, targeted therapy

\section{Introduction}

Lung cancer is currently the most common cancer diagnosis and the leading cause of cancer-related death worldwide. ${ }^{1}$ Brain metastasis is usual in non-small-cell lung cancer (NSCLC) and 30\%-50\% patients may develop brain metastases at some point during their disease courses. ${ }^{2,3}$ Few therapeutic options are available for brain metastases and the prognosis of NSCLC patients with brain metastasis is still poor. Brain metastasis has become a critical issue and more novel strategies are urgently needed.

The epidermal growth factor receptor-tyrosine kinase inhibitors (EGFR-TKIs) gefitinib and erlotinib have been proved to be effective in improving tumor response and increasing survival for advanced NSCLC. ${ }^{4-9}$ Moreover, it has been found that activating EGFR mutations within the tyrosine kinase domain in NSCLC are highly associated with the sensitivity to EGFR-TKI treatment, which has emerged as an important predictor of response and survival benefit in NSCLC. ${ }^{5,10-14}$ To date, EGFR-TKI has become the standard treatment option for NSCLC with activating EGFR mutation.

Since there are more effective molecular targeted agents in the treatment for some subsets of NSCLC compared to the conventional therapy, increasing attention has been paid to the potential role of EGFR-TKI in brain metastases from NSCLC in recent 
years. Nonetheless, brain metastases were usually considered as exclusion criteria in most previous clinical studies involving EGFR-TKI and accounts of its use in intracranial lesions are available only in a few case reports or some small studies with limited number of patients. Therefore, the role of EGFR-TKI in this setting still remains unclear. The purpose of this retrospective study was to further explore the antitumor efficacy of EGFR-TKI therapy against brain metastases from NSCLC harboring EGFR mutation.

\section{Methods}

\section{Study design and patients}

This study was approved by the Institutional Review Board of Shanghai Chest Hospital, which waived the need to obtain patient consent due to the retrospective nature of the study that had no potential benefit or harm to the patients. From January 2006 to June 2016, 1,076 NSCLC patients with brain metastases were screened in Shanghai Chest Hospital, 324 of whom once received the EGFR-TKI treatment for brain metastases. Inclusion criteria were as follows: 1) patients were pathologically diagnosed with lung adenocarcinoma harboring EGFR mutation in exon 19 or 21 ; 2) brain metastases were confirmed by contrast-enhanced magnetic resonance imaging (MRI); 3) the patients had extracranial diseases including primary lung tumor and other metastases; 4) there was at least one measurable lesion for both intracranial and extracranial diseases; 5) the patients received gefitinib or erlotinib therapy following failure in prior brain irradiation with or without chemotherapy; 6) the interval from the end of brain irradiation to the start of oral TKI was at least 4 weeks; 7) no patients received a target therapy before the occurrence of brain metastases; 8) radiotherapy, interventional therapy, and other local treatments were not administered during the EGFR-TKI therapy; and 9) the patients had complete follow-up data. Thus, a total of 148 patients were eligible for assessment in this study.

Baseline characteristics of the patients were retrieved from medical records within 4 weeks before the EGFR-TKI treatment, including age, sex, smoking history, an Eastern Cooperative Oncology Group performance status (ECGO PS), recursive portioning analysis (RPA) class, number of brain metastases, initial brain symptoms, type of prior brain irradiation, prior chemotherapy, EGFR mutation status, and kind of EGFR-TKI.

All patients were orally given gefitinib $250 \mathrm{mg}$ or erlotinib $150 \mathrm{mg}$ once a day until intracranial disease progression (morphologically confirmed intracranial disease progression or the deterioration of symptomatic brain metastases clinically), death, or unacceptable toxicity. Median time from the end of brain irradiation to the beginning of EGFR-TKI intake was 4.7 months (range, 1.4-29.3 months).

\section{Response assessment and toxicity evaluation}

Radiological images (MRI for intracranial diseases and computed tomography scan for extracranial diseases) were first taken 1 month after the beginning of EGFR-TKI intake and were routinely taken every 2 months or when clinically indicated thereafter.

Tumor response was assessed as complete response (CR), partial response (PR), stable disease (SD), or progressive disease (PD), in accordance with the standard Response Evaluation Criteria in Solid Tumors (version 1.1). ${ }^{15}$ The objective response rate (ORR) was defined as CR plus $\mathrm{PR}$. The disease control rate (DCR) was defined as the best tumor response of CR, PR, or SD.

The toxicity of EGFR-TKI was evaluated by reviewing the documented medical records at each clinical visit. All toxicities, including skin rash, diarrhea, hepatotoxicity, and radiological evidence of interstitial pneumonitis, were graded according to the National Cancer Institute Common Terminology Criteria for Adverse Events version 3.0 (CTCAE3.0). ${ }^{16}$

\section{Statistical methods}

The progression-free survival (PFS) was measured from the first day of EGFR-TKI intake to the documented progression within brain, or death from any cause. The overall survival (OS) was determined from the first date of EGFR-TKI intake to the date of death from any cause, or the last survival follow-up. The last follow-up date was August 30, 2016.

SPSS software version 11.0 for Windows was used for the statistical analysis. Differences among response rates were analyzed by the chi-squared test. Actuarial progression and survival curves were calculated using the Kaplan-Meier method. The impact of the potential variables affecting PFS and OS was assessed by the univariate analysis with the logrank test. The multivariate survival analysis was performed using the Cox proportional hazard method by entering all significant variables from the univariate analysis. Statistical significance was defined as $P<0.05$.

\section{Results}

\section{Patient characteristics}

The patients' baseline characteristics are summarized in Table 1, which include median age, 55 years (range, 28-77 years); 98 females and 50 males; 109 nonsmokers and 39 former or current smokers; 72 with PS $0-1$ and 76 with PS 2-3; 99 with RPA class I-II and 49 with RPA class 
Table I Patients' characteristics

\begin{tabular}{|c|c|c|}
\hline Characteristic & $\mathbf{N}$ & $\%$ \\
\hline Age (years), Median (range) & $55(28-77)$ & \\
\hline$<65$ & 107 & 72.3 \\
\hline$\geq 65$ & 41 & 27.7 \\
\hline \multicolumn{3}{|l|}{ Sex } \\
\hline Female & 98 & 66.2 \\
\hline Male & 50 & 33.8 \\
\hline \multicolumn{3}{|l|}{ Smoking history } \\
\hline Never smokers & 109 & 73.6 \\
\hline Former or current smokers & 39 & 26.4 \\
\hline \multicolumn{3}{|l|}{ ECGO PS } \\
\hline $0-1$ & 72 & 48.6 \\
\hline $2-3$ & 76 & 51.4 \\
\hline \multicolumn{3}{|l|}{ RPA class } \\
\hline I-II & 99 & 66.9 \\
\hline III & 49 & 33.1 \\
\hline \multicolumn{3}{|l|}{ Number of metastases } \\
\hline Single & 51 & 34.5 \\
\hline Multiple & 97 & 65.5 \\
\hline \multicolumn{3}{|l|}{ Initial brain symptoms } \\
\hline Yes & 101 & 68.2 \\
\hline No & 47 & 31.8 \\
\hline \multicolumn{3}{|l|}{ Prior brain irradiation } \\
\hline SRS only & 37 & 25.0 \\
\hline SRS + WBRT & 22 & 14.9 \\
\hline WBRT only & 89 & 60.1 \\
\hline \multicolumn{3}{|l|}{ Prior chemotherapy } \\
\hline Yes & 123 & 83.1 \\
\hline No & 25 & 16.9 \\
\hline \multicolumn{3}{|l|}{ EGFR mutation } \\
\hline Exon 19 & 88 & 59.5 \\
\hline Exon 21 & 60 & 40.5 \\
\hline \multicolumn{3}{|l|}{ EGFR-TKI } \\
\hline Gefitinib & 95 & 60.8 \\
\hline Erlotinib & 53 & 39.2 \\
\hline
\end{tabular}

Abbreviations: ECGO PS, Eastern Cooperative Oncology Group performance status; EGFR, epidermal growth factor receptor; RPA, recursive portioning analysis; SRS, stereotactic radiosurgery; TKI, tyrosine kinase inhibitor; WBRT, whole-brain radiation therapy.

III; 97 with multiple intracranial lesions and 51 with a single intracranial lesion; 101 with metastatic brain symptoms and 47 without metastatic brain symptoms; 37 pretreated with stereotactic radiosurgery (SRS) only, 22 pretreated with SRS followed by whole-brain radiation therapy (WBRT), and 89 pretreated with WBRT only; 123 with prior chemotherapy and 25 without chemotherapy; 88 with in-frame deletion mutation in exons 19 and 60 with a point mutation (L858R) in exon 21; and 95 with oral gefitinib and 53 with oral erlotinib.

\section{Response assessment and survival data}

No patient achieved CR in the study. Among them, for intracranial diseases, 54 achieved PR, 75 obtained SD, and 19 had PD, yielding an ORR of $36.5 \%$ and a DCR of $87.2 \%$; for extracranial diseases, 62 achieved PR, 72 obtained SD,
Table 2 Response of intracranial and extracranial diseases

\begin{tabular}{llllll}
\hline & \multicolumn{2}{l}{$\begin{array}{l}\text { Intracranial } \\
\text { response }\end{array}$} & & \multicolumn{2}{l}{$\begin{array}{l}\text { Extracranial } \\
\text { response }\end{array}$} \\
\cline { 2 - 3 } \cline { 6 - 7 } & $\mathbf{n}$ & & & $\mathbf{n}$ & $\%$ \\
\hline $\mathrm{CR}$ & 0 & 0 & & 0 & 0 \\
$\mathrm{PR}$ & 54 & 36.5 & & 62 & 41.9 \\
$\mathrm{SD}$ & 75 & 50.7 & & 72 & 48.6 \\
$\mathrm{PD}$ & 19 & 12.8 & & 14 & 9.5 \\
\hline
\end{tabular}

Abbreviations: CR, complete response; PD, progressive disease; PR, partia response; SD, stable disease.

and 14 had PD, yielding an ORR of $41.9 \%$ and a DCR of 90.5\% (Table 2). The median PFS and OS of the entire series were 11.2 months (95\% CI, 10.1-12.3) (Figure 1) and 13.6 months (95\% CI, 12.3-14.9) (Figure 2), respectively. The patients' characteristics were not statistically associated with PFS and OS.

The difference in the intracranial efficacy outcomes by the two EGFR-TKIs was also analyzed. Out of the 95 patients receiving gefitinib, there were $33 \mathrm{PRs}$ and $49 \mathrm{SDs}$ with a DCR of $86.3 \%$ while, out of the 53 patients receiving erlotinib, there were $21 \mathrm{PRs}$ and $26 \mathrm{SDs}$ with a DCR of $88.7 \%(P=0.813)$. There was no statistical difference in the median PFS (11.3 vs 10.8 months, $P=0.2030)$ and $\mathrm{OS}(13.8$ vs 13.5 months, $P=0.3185)$ between the gefitinib and the erlotinib group (Table 3 ).

\section{Toxicity}

In the entire series, 105 patients $(70.9 \%)$ had at least one type of drug-related toxicity. Rash was the most common side

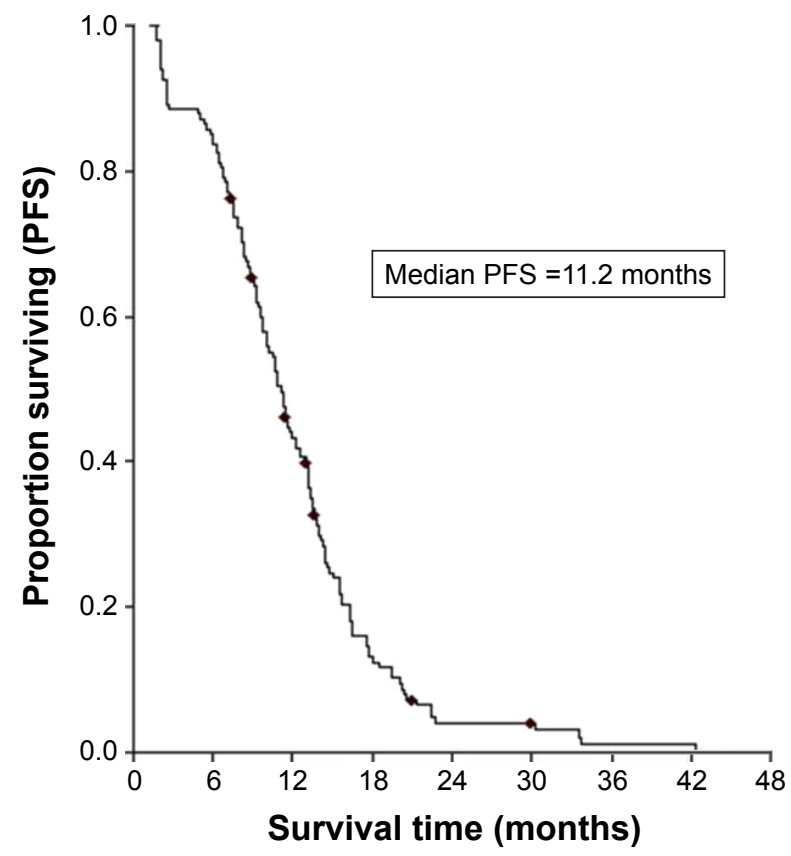

Figure I PFS of patients treated with EGFR-TKIs.

Abbreviations: EGFR, epidermal growth factor receptor; TKI, tyrosine kinase inhibitor; PFS, progression-free survival. 


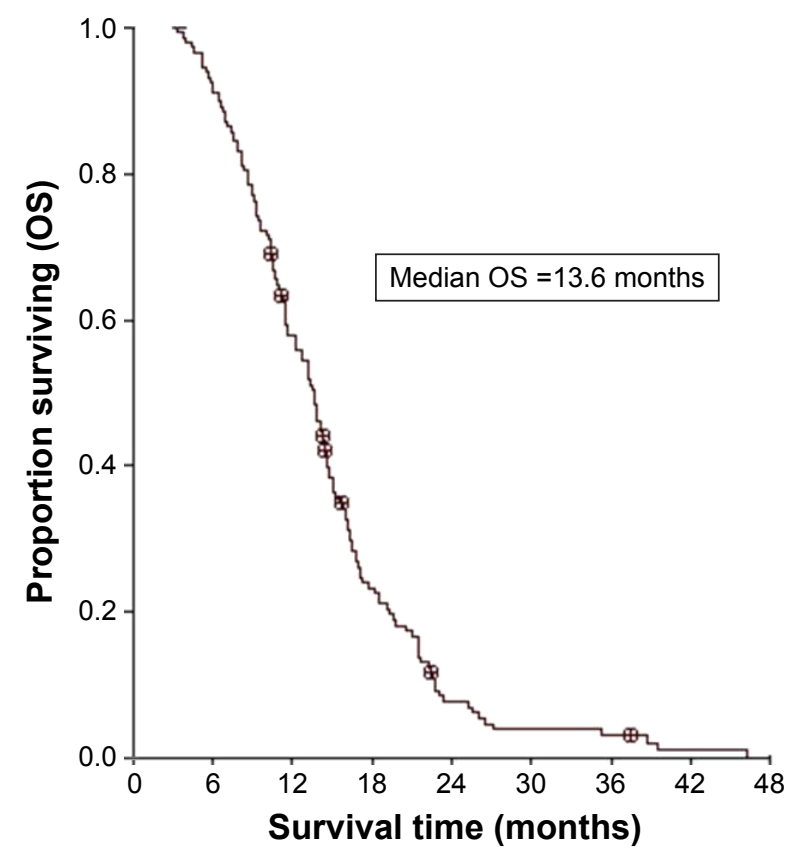

Figure 2 OS of patients treated with EGFR-TKIs.

Abbreviations: EGFR, epidermal growth factor receptor; TKI, tyrosine kinase inhibitor; OS, overall survival.

effect (62.8\%), followed by diarrhea (38.5\%), fatigue (27.7\%), hepatotoxicity (20.9\%), nausea (16.9\%), and vomiting $(4.7 \%)$. Most side effects were grade 1-2 and no interstitial lung disease events were encountered. Seventeen patients $(11.5 \%)$ experienced grade 3-4 toxicities mainly including rash, hepatotoxicity, and diarrhea (eight with grade 3-4 rashes, six with grade 3 hepatotoxicity, and three with grade 3 diarrhea), 12 $(8.1 \%)$ of whom required dose reduction (seven in the gefitinib group and five in the erlotinib group), which was sufficient to decrease the toxicity to grade 2 . No patient stopped the EGFR-TKI treatment due to the side effects.

\section{Discussion}

The therapeutic efficacy of EGFR-TKI in NSCLC with activating EGFR mutation is now widely recognized. Recently,

Table 3 Response of gefitinib and erlotinib against intracranial diseases and survival data

\begin{tabular}{llllll}
\hline & Gefitinib & & & Erlotinib \\
\cline { 2 - 3 } \cline { 6 - 7 } & $\mathbf{n}$ & $\%$ & & $\mathbf{n}$ & $\%$ \\
\hline CR & 0 & 0 & & 0 & 0 \\
PR & 33 & 34.7 & & 21 & 39.6 \\
SD & 49 & 51.6 & & 26 & 49.1 \\
PD & 13 & 13.7 & & 6 & 11.3 \\
MPFS (months) & 11.3 & & & 10.8 & \\
MOS (months) & 13.8 & & & 13.5 & \\
\hline
\end{tabular}

Abbreviations: CR, complete response; MOS, median overall survival; MPFS, median progression-free survival; PD, progressive disease; PR, partial response; SD, stable disease. more interest has been shown in EGFR-TKI against brain metastases from NSCLC. However, data in this regard have mainly been limited to some individual case reports or small case series studies, in which the reported ORR (range, 69\%-88\%), DCR (range, 82\%-100\%), PFS (range, 6.6-14.5 months), and OS (range, 12.9-21.9 months) varied considerably. ${ }^{17-23}$

In this study, ORR was $36.5 \%$ and DCR was $87.2 \%$ within the brain lesions, with a median PFS of 11.2 months and OS of 13.6 months, respectively. In contrast, the ORR of $36.5 \%$ within brain was lower than that reported by other authors while DCR, PFS, and OS were of similar magnitude to those mentioned above. The difference may be partly due to several reasons, such as the inclusion criteria of the study, the number of enrolled patients, the therapy timing in EGFR-TKI treatment lines, the examination method of EGFR mutation, and the patients' individual differences. Despite the relatively lower ORR within brain in this study, DCR, PFS, and OS were not inferior to previous reports. In our opinion, the emphasis of clinical evaluation of EGFR-TKI against brain lesions should be placed not only on short-term tumor response but also on long-term survival benefit. As we know, brain radiotherapy could improve the permeability of the blood brain-barrier (BBB) and help TKI cross the BBB. ${ }^{24}$ This may be one of the reasons why the patients pretreated with brain irradiation could benefit from TKIs. Moreover, as the most important and favorable prognostic factor, the impact of activating EGFR mutation might have masked the influence of other variables in the statistical analysis. Thus, no significant differences in PFS and OS related to the patients' characteristics were detected in this study. Furthermore, EGFR-TKI was selected as a second- or third-line therapy for brain metastases in this study. This means that the patients lacked other effective options subsequently, in the case of disease progression after the TKI treatment. This may explain why PFS was almost the same as OS of the patients.

In addition to the EGFR-TKI efficacy within brain, the extracranial response was also evaluated in this study. The data showed that ORR and DCR in the intracranial and extracranial diseases were $36.5 \%, 87.2 \%$ and $41.9 \%, 90.5 \%$, respectively. The efficacy of EGFR-TKI in intracranial lesions was paralleled by its efficacy in extracranial lesions, which confirms the results of some reports. ${ }^{18,23}$ This indicates that the patients with activating EGFR mutation responding to EGFR-TKI within brain also responded in extracranial lesions. Unlike local therapies that induce intracranial response only, EGFR-TKI is active for both intracranial and extracranial lesions, which could definitely supplement the traditional treatment for brain metastases from NSCLC. 
The tolerability of EGFR-TKI in patients with brain metastases has not been specifically addressed before. In this study, 105 patients $(70.9 \%)$ experienced at least one type of drug-related toxicity, which were usually mild or moderate in intensity. Rash and diarrhea were the most common adverse events and no patient stopped the TKI therapy due to toxicity. Like those descriptions of drug-related side effects in earlier studies that excluded patients with brain metastases, ${ }^{4,5,8,9}$ this study shows that both EGFR-TKIs are generally well tolerated in patients with brain metastases.

It might be expected that the $E G F R$ mutation status would be discordant between primary tumors and brain metastases due to the heterogeneity of tumor cells. ${ }^{25-28}$ In such a situation, the response discrepancy between intracranial and extracranial lesions may exit when EGFR-TKI is used. ${ }^{29,30}$ It is debatable whether it is reasonable to use EGFR-TKI for brain metastases based on the EGFR mutation in lung tumor. In this study, all samples for the EGFR mutation analysis were obtained from primary lung tumors. Interestingly, the data from this study showed that the patients achieved an intracranial DCR of $87.2 \%$ with a similar extracranial DCR of $90.5 \%$ and most patients who had responses in intracranial lesions also attained responses in extracranial lesions. This finding supports the hypothesis that the EGFR mutation in lung tumors could be related to the EGFR-TKI response even in the presence of brain metastases. ${ }^{17-23}$ It suggests the antitumor role of EGFR-TKI against brain metastases dependent on the EGFR mutation from lung tissue, while the $E G F R$ status in brain lesions is not determined. In fact, considering that surgical resection on metastatic brain tumors can only be indicated for a limited number of patients, ${ }^{31-33}$ it is impossible to get brain tumor tissues for the EGFR mutation analysis in most cases. In our view, it may be feasible in a clinical setting that the EGFR mutation status in lung tumor could be regarded as an indicator for EGFR-TKI against brain metastases. Of course, the relationship between $E G F R$ mutation status of primary NSCLC and that of matched brain metastases should be further explored.

Gefitinib and erlotinib are the two frequently used EGFR-TKIs in the treatment for NSCLC. In a recently published randomized phase II study of gefitinib versus erlotinib in locally advanced, metastatic NSCLC patients following failure in previous first-line chemotherapy, both drugs demonstrated a comparable clinical activity with no significant difference in the response rate or PFS, and an acceptable safety profile. ${ }^{34}$ It is of interest to compare the obtained results of gefitinib with those of erlotinib against brain metastases. In this study, there was no statistical difference in terms of ORR, DCR, PFS, and OS between the gefitinib and the erlotinib group. Moreover, a non-significant trend toward more severe skin toxicity and hepatotoxicity in patients treated with gefitinib or erlotinib was observed. As a result, it cannot be identified which TKI is superior or inferior, which is similar to some isolated reports. ${ }^{18,35,36}$ Overall, the lack of clinical data available for distinct patient populations limited the conclusions of the assessment.

The major limitations of this study were its retrospective, nonrandomized design and single-institution study population. Although the efficacy and safety data from this study are promising, it is wise to take into consideration the limitations of this study when interpreting the results.

In conclusion, the results of this study suggest that EGFR-TKIs show a promising antitumor activity in treating brain metastases from NSCLC harboring activating EGFR mutations with an acceptable safety profile, meaning the EGFR-TKI therapy can be a novel option in this group of patients. Further randomized and prospective trials are warranted to validate the findings.

\section{Author contribution}

All authors contributed toward data analysis, drafting, and revising the paper and agree to be accountable for all aspects of the work.

\section{Disclosure}

The authors report no conflicts of interest in this work.

\section{References}

1. Torre LA, Bray F, Siegel RL, Ferlay J, Lortet-Tieulent J, Jemal A. Global cancer statistics, 2012. CA Cancer J Clin. 2015;65:87-108.

2. Villarreal-Garza C, de la Mata D, Zavala DG, Macedo-Perez EO, Arrieta O. Aggressive treatment of primary tumor in patients with non-small-cell lung cancer and exclusively brain metastases. Clin Lung Cancer. 2013;14:6-13.

3. Socinski MA, Evans T, Gettinger S, et al. Treatment of stage IV nonsmall cell lung cancer: diagnosis and management of lung cancer, $3 \mathrm{rd}$ ed: American College of Chest Physicians evidence-based clinical practice guidelines. Chest. 2013;143:e341S-e368S.

4. Shepherd FA, Pereira J, Ciuleanu T, et al; National Cancer Institute of Canada Clinical Trials Group. Erlotinib in previously treated non-smallcell lung cancer. N Engl J Med. 2005;353:123-132.

5. Mok TS, Wu YL, Thongprasert S, et al. Gefitinib or carboplatin-paclitaxel in pulmonary adenocarcinoma. $N$ Engl J Med. 2009;361:947-957.

6. Maemondo M, Inoue A, Kobayashi K, et al; North-East Japan Study Group. Gefitinib or chemotherapy for non-small-cell lung cancer with mutated EGFR. N Engl J Med. 2010;362:2380-2388.

7. Cappuzzo F, Ciuleanu T, Stelmakh L, et al; SATURN Investigators. Erlotinib as maintenance treatment in advanced non-small-cell lung cancer: a multicentre, randomised, placebo-controlled phase 3 study. Lancet Oncol. 2010;11:521-529.

8. Han JY, Park K, Kim SW, et al. First-SIGNAL: first-line single-agent iressa versus gemcitabine and cisplatin trial in never-smokers with adenocarcinoma of the lung. J Clin Oncol. 2012;30:1122-1128. 
9. Rosell R, Carcereny E, Gervais R, et al; Spanish Lung Cancer Group in collaboration with Groupe Français de Pneumo-Cancérologie and Associazione Italiana Oncologia Toracica. Erlotinib versus standard chemotherapy as first-line treatment for European patients with advanced EGFR mutation-positive non-small-cell lung cancer (EURTAC): a multicentre, open-label, randomised phase 3 trial. Lancet Oncol. 2012;13:239-246.

10. Rosell R, Moran T, Queralt C, et al; Spanish Lung Cancer Group. Screening for epidermal growth factor receptor mutations in lung cancer. N Engl J Med. 2009;361:958-967.

11. Paz-Ares L, Soulières D, Melezinek I, et al. Clinical outcomes in nonsmall-cell lung cancer patients with EGFR mutations: pooled analysis. J Cell Mol Med. 2010;14:51-69.

12. Mitsudomi T, Mortia S, Yatabe Y, et al; West Japan Oncology Group. Gefitinib versus cisplatin plus docetaxel in patients with non-smallcell lung cancer harbouring mutations of the epidermal growth factor receptor (WJTOG3405): an open label, randomised phase 3 trial. Lancet Oncol. 2010;11:121-128.

13. Pallis AG, Fennell DA, Szutowicz E, Leighl NB, Greillier L, Dziadziuszko R. Biomarkers of clinical benefit for anti-epidermal growth factor receptor agents in patients with non-small-cell lung cancer. Br J Cancer. 2011;105:1-8.

14. Petrelli F, Borgonovo K, Cabiddu M, Barni S. Efficacy of EGFR tyrosine kinase inhibitors in patients with EGFR-mutated non-small cell-lung cancer: a meta-analysis of 13 randomized trials. Clin Lung Cancer. 2012;13:107-114.

15. Eisenhauer EA, Therasse P, Bogaerts J, et al. New response evaluation criteria in solid tumours: revised RECIST guideline (version 1.1). Eur J Cancer. 2009;45:228-247.

16. Trotti A, Colevas AD, Setser A, et al. CTCAE v3.0: development of a comprehensive grading system for the adverse effects of cancer treatment. Semin Radiat Oncol. 2003;13:176- 181.

17. Porta R, Sánchez-Torres JM, Paz-Ares L, et al. Brain metastases from lung cancer responding to erlotinib: the importance of EGFR mutation. Eur Respir J. 2011;37:624-631.

18. Park SJ, Kim HT, Lee DH, et al. Efficacy of epidermal growth factor receptor tyrosine kinase inhibitors for brain metastasis in non-small cell lung cancer patients harboring either exon 19 or 21 mutation. Lung cancer. 2012;77:556-560

19. Iuchi T, Shingyoji M, Sakaida T, et al. Phase II trial of gefitinib alone without radiation therapy for Japanese patients with brain metastases from EGFR-mutant lung adenocarcinoma. Lung Cancer. 2013; $82: 282-287$

20. Fan Y, Xu X, Xie C. EGFR-YKI therapy for patients with brain metastases from non-small-cell lung cancer: a pooled analysis of published data. Onco Targets Ther. 2014;10:2075-2084.

21. Eichler AF, Kahle KT, Wang DL, et al. EGFR mutation status and survival after diagnosis of brain metastasis in nonsmall cell lung cancer. Neuro Oncol. 2010;12:1193-1199.

22. Welsh JW, Komaki R, Amini A, et al. Phase II trial of erlotinib plus concurrent whole-brain radiation therapy for patients with brain metastases from non-small-cell lung cancer. J Clin Oncol. 2013;31:895-902.
23. Wu YL, Zhou C, Cheng Y, et al. Erlotinib as second-line treatment in patients with advanced non-small-cell lung cancer and asymptomatic brain metastases: a phase II study (CTONG-0803). Ann Oncol. 2013; 24:993-999.

24. Fauquette W, Amourette C, Dehouck MP, Diserbo M. Radiationinduced blood-brain barrier damages: an in vitro study. Brain Res. 2012; 1433:114-126.

25. Taniguchi K, Okami J, Kodama K, Higashiyama M, Kato K. Intratumor heterogeneity of epidermal growth factor receptor mutations in lung cancer and its correlation to the response to gefitinib. Cancer Sci. 2008;99:929-935

26. Park S, Holmes-Tisch AJ, Cho EY, et al. Discordance of molecular biomarkers associated with epidermal growth factor receptor pathway between primary tumors and lymph node metastasis in non-small cell lung cancer. J Thorac Oncol. 2009;4:809-815.

27. Gow $\mathrm{CH}$, Chang YL, Hsu YC, et al. Comparison of epidermal growth factor receptor mutations between primary and corresponding metastatic tumors in tyrosine kinase inhibitor-naive non-small-cell lung cancer. Ann Oncol. 2009;20:696-702.

28. Gomez-Roca C, Raynaud CM, Penault-Llorca F, et al. Differential expression of biomarkers in primary non-small cell lung cancer and metastatic sites. J Thorac Oncol. 2009;4:1212-1220.

29. Daniele L, Cassoni P, Bacillo E, et al. Epidermal growth factor receptor gene in primary tumor and metastatic sites from non-small cell lung cancer. J Thorac Oncol. 2009;4:684-688.

30. Sun M, Behrens C, Feng L, et al. HER family receptor abnormalities in lung cancer brain metastases and corresponding primary tumors. Clin Cancer Res. 2009;15:4829-4837.

31. Baykara M, Kurt G, Buyukberber S, et al. Management of brain metastases from non-small cell lung cancer. J Cancer Res Ther. 2014;10: 915-921.

32. Pruitt AA. Medical management of patients with brain tumors. Curr Treat Options Neurol. 2011;13:413-426.

33. Taso MN, Rades D, Wirth A, et al. Radiotherapeutic and surgical management for newly diagnosed brain metastasis(es): an American Society for Radiation Oncology evidence-based guideline. Pract Radiat Oncol. 2012;2:210-225.

34. Kim ST, Uhm JE, Lee J, et al. Randomized phase II study of gefitinib versus erlotinib in patients with advanced non-small cell lung cancer who failed previous chemotherapy. Lung Cancer. 2012;75:82-88.

35. Kim JE, Lee DH, Choi,Y et al. Epidermal growth factor receptor tyrosine kinase inhibitors as a first-line therapy for never-smokers with adenocarcinoma of the lung having asymptomatic synchronous brain metastasis. Lung Cancer. 2009;65:351-354.

36. Heon S, Yeap BY, Britt GJ, et al. Development of central nervous system metastases in patients with advanced non-small cell lung cancer and somatic EGFR mutations treated with gefitinib or erlotinib. Clin Cancer Res. 2010;16:5873-5882.
OncoTargets and Therapy

\section{Publish your work in this journal}

OncoTargets and Therapy is an international, peer-reviewed, open access journal focusing on the pathological basis of all cancers, potential targets for therapy and treatment protocols employed to improve the management of cancer patients. The journal also focuses on the impact of management programs and new therapeutic agents and protocols on
Dovepress

patient perspectives such as quality of life, adherence and satisfaction The manuscript management system is completely online and includes a very quick and fair peer-review system, which is all easy to use. Visit http://www.dovepress.com/testimonials.php to read real quotes from published authors. 